\title{
An Investigation of Formulaic Sequences in Multi-modal Chinese College English Textbooks
}

\author{
Haiyan Miao \\ Jiangxi Normal University, Nanchang, China
}

\begin{abstract}
The paper explores the distributional and acquisitional characteristics of formulaic sequences in typically multi-modal textbooks most popularly used in English teaching in China. Research results indicate that the frequency of formulaic sequences in the listening-speaking textbook is significantly higher than that of the reading-writing textbook. Furthermore, the two different modal textbooks differ in both the categories and the functions of formulaic sequences. However, Chinese English learners are generally not sensitive to these differences. In addition, there exists a plateau effect in their acquisition of textbook formulaic sequences, as there is no significant difference between learners of different proficiency levels. These findings reveal the significance of highlighting register differences between reading-writing and listening-speaking, thus shedding light on the input and output problems in college English teaching and learning.
\end{abstract}

Index Terms—reading-writing textbook, listening-speaking textbook, chunk, frequency

\section{INTRODUCTION}

Formulaic sequences are pre-fabricated language that can be stored, retrieved and used as a whole without the need to compose them on-line through much consideration of word choice and grammar. In recent years, the role of formulaic sequences has been highlighted by many scholars and researchers, because possibly as much as $70 \%$ of the adult native language may be formulaic sequences (c.f. Wray \& Perkins, 2000), and much of lexis consists of sequences of words operating as single units (Schmitt, 2000).

Great importance has been attached to formulaic sequences in Chinese English textbooks. Yang (2012), editor-in-chief of a series of popular English textbooks, points out that textbook compilation and learning should emphasize the significance of formulaic sequences which pave the way for idiomatic expression and native-like choices. In China, one of the most important aims of college English learning is to foster competence in different registers like reading-writing and listening-speaking. It follows that college English learning is usually divided into two sections, that is, the teaching of reading-writing and the teaching of listening-speaking, which require then different modal textbooks in classrooms. Since textbooks are the most straight and important source of language input, study of formulaic sequences in textbooks would provide insights into the pedagogical values of formulaic sequences, and the specific requirements of different registers, so that implications can be revealed for the learning and teaching of English as a foreign language in China.

\section{LITERATURE REVIEW}

Miller (1956) introduces the "magic number" $7 \pm 2$, namely the number of formulaic sequences that can be held in STM for immediate recall. Following Miller's work, many psychologists have approached the importance of chunk in memory through the differences between LTM and STM, and it is becoming a trend to introduce formulaic sequences into the areas of language learning and vocabulary acquisition. Since the flooding research in formulaic sequences from 1970s, more recent researches are focusing on the characteristics of formulaic sequences and the related pedagogical values with the help of corpus technology.

Koprowski (2005) explores the practicality of formulaic sequences in three contemporary main stream English textbooks, but finds that these three textbooks are very limited in pedagogical values of formulaic sequences. With pedagogical values in mind, Koprowski then tries to offer suggestions for each textbook about the chunk distribution and constructing. Biber (2006) systematically studies register differences between formulaic sequences in oral and written productions, by comparing the category and function distributions in college textbooks and the college teaching process. Simpson-Vlach \& Ellis (2010), adopting the standards of frequency and distribution range, proposes an academic chunk list which is both pedagogically valuable and meaningful for academic English teaching. Martinez \& Schmitt (2012), in accordance with high frequency and pedagogical value, discusses receptive chunk list construction in the hope of providing insights for textbook compilation and chunk teaching in general language teaching. Gray \& Biber (2013) uses corpus technology to study continuous and discontinuous formulaic sequences in oral and written productions with a focus on different register functions of formulaic sequences.

Study on formulaic sequences in China has also witnessed an increasing tendency in the following three areas. First is the categorization and introduction of formulaic sequences (Ma, 2011; Huang \& Wang, 2011). Then is the descriptive 
study of the characteristics of chunk usage in Chinese EFL learners' interlanguage (Ding \& Qi, 2005; Ma, 2009), as well as exploration of their chunk acquisition model (Qu \& Deng, 2010). Chunk research in ESP also attracts attention from Chinese scholars (Wang \& Liu, 2013). As for formulaic sequences in textbooks and their pedagogical values, little research has been conducted in mainland China, which is evidenced by the fact that only one article has been published in one of the most distinguished foreign language journals (Chen \& Chen, 2011). Chen \& Chen (2011), from the perspective of EAP, compare chunk distribution between EAP textbooks and general English language textbooks. Therefore, it seems that more research into textbook formulaic sequences is urgently needed for suggestions of the organization and reconstructing of language teaching and learning. In this paper, we will explore formulaic sequences in general English textbooks in order to see whether there are register differences in different modal Chinese English textbooks. Our research questions are:

(1) What are the characteristics of formulaic sequences' distribution in multi-modal Chinese English textbooks?

(2) Are there any differences in the categories and functions of formulaic sequences in multi-modal Chinese English textbooks?

(3) Can Chinese well distinguish the above differences if any in formulaic sequences in their language output?

\section{RESEARCH DESIGN}

\section{A. Research Corpus}

Since EFL in the Chinese setting is skill-oriented, learners have two different modal English textbooks for the first two years in college when English is the compulsory course. One mode is the integrated textbook which aims mainly at promoting learners' reading and writing abilities. The other mode is the listening-speaking textbook which focuses on the fostering of listening and speaking abilities. The college English textbooks in contemporary use are chosen as the subjects of investigation. The integrated textbook is New College English (Second Edition), while the listening-speaking textbook is Learning to Speak: An English Video Course (Third Edition). Both of these textbooks are published by Shanghai Foreign Language Education Press. For the integrated course, there are four books for the four semesters respectively in the first two years in college. Each book contains 8 units, with 2 texts per unit and thus altogether 64 texts (73887 tokens) for four books. Similarly, the listening-speaking course encompasses 4 books, with each book containing 8 units. In each unit, there are two lessons, namely Lesson A and Lesson B, thus altogether 64 lessons of 97766 tokens.

\section{B. Research Procedures}

Through concordances of 3-word cluster formulaic sequences by AntConc3.2.4, the present study lists the top 100 formulaic sequences in the integrated and listening-speaking textbooks respectively. Methods such as means comparisons and independent $\mathrm{T}$ tests are then used to analyze the distributional characteristics of formulaic sequences in the two modal textbooks. Based on Hyland (2008), analysis is conducted as for the categories and functions of formulaic sequences in the two different textbooks. Then learners' acquisition of formulaic sequences from the two different modal textbooks is evidenced by concordances of the college English sub-corpus of the Chinese Learners English Corpus (CLEC), which consists of compositions from EFL learners of various proficiency levels. What follows next is the possible pedagogical implication for language input and output in EFL in the Chinese setting.

\section{Results}

\section{A. Distribution of Formulaic Sequences}

With cluster size set at 3, the program AntConc works out all the related formulaic sequences in the integrated and listening-speaking textbooks from the most frequent to the least frequent ones. However, due to limitations in space, Table 1 and Table 2 only present the top 30 formulaic sequences in the two modal textbooks respectively. By comparing Table 1 and Table, it can be seen that these two modal textbooks differ in three aspects. First is frequency. Formulaic sequences occur in the listening-speaking textbook far more frequently than in the integrated textbook. The most frequent formulaic sequence in the integrated textbook is 30 , the least frequent 8 . On the other hand, the most frequent formulaic sequence in the listening-speaking textbook is 187 , the least frequent is 33 . Besides, there are overlapping formulaic sequences that occur both in the integrated and listening-speaking textbooks, but with different frequencies. For instance, I don't ranks highest in both textbooks, with 30 in the integrated textbook and 187 in the listening-speaking textbook. One of the is the second most frequent in the integrated textbook but 22 most frequent in the listening-speaking textbook. Last but not least, prepositional and noun formulaic sequences tend to occur in the integrated textbook, for example, out of the, in front of and the rest of. Verb formulaic sequences, such as am going to and go to the, appear more in the listening-speaking textbook.

Table 3 and Table 4 show the means of formulaic sequences' frequency and the result of the Independent $T$ test respectively. From Table 3, it can be seen that there is difference in the means of formulaic sequences' frequency, as the frequency means for the integrated textbook is 8.67 and 35.5 for the listening-speaking textbook. Independent T test (Table 4) results prove the above difference is statistically significant $(\mathrm{F}=35.114$, Sig. $=0.000)$, which means that formulaic sequences occur significantly more frequent in the listening-speaking textbook than in the integrated 
textbook.

TABLE 1

TOP 30 FORMULAIC SEQUENCES IN THE INTEGRATED TEXTBOOK

\begin{tabular}{|c|c|c|}
\hline I don’t (30) & Seemed to be (11) & I'm not (9) \\
\hline One of the (22) & In the United (10) & I told him (9) \\
\hline The United States (16) & Of the world (10) & I wanted to (9) \\
\hline A lot of (15) & The rest of (10) & That he had (9) \\
\hline I didn’t (15) & To be a $(10)$ & The end of (9) \\
\hline Out of the (15) & Back to the (9) & The University of (9) \\
\hline I couldn't (12) & Be able to (9) & To make a (9) \\
\hline I had to (11) & End of the (9) & A man who (8) \\
\hline In the world & For me to (9) & As well as (8) \\
\hline It's a (11) & He didn't (9) & In front of (8) \\
\hline
\end{tabular}

TABLE 2.

TOP 30 FORMULAIC SEQUENCES IN THE LISTENING-SPEAKING TEXTBOOK

\begin{tabular}{lll}
\hline I don't (187) & The blanks with (49) & Fill in the (36) \\
A lot of (137) & I'm not (48) & I think it (36) \\
Listen to the (108) & It's a (47) & Blanks with what (35) \\
I'm going (66) & I didn't (45) & Don't have (35) \\
I can't (65) & I have a (44) & It's a (35) \\
In the blanks (62) & What do you (41) & Is going to (35) \\
Don't know (61) & Go to the (40) & With what you (35) \\
Am going to (57) & Fill in the (37) & Don't like (34) \\
I'm a (50) & What you hear (37) & Now listen to (34) \\
I want to (50) & would like to (36) & One of the (33) \\
\hline
\end{tabular}

TABLE 3.

MEANS COMPARISON OF FORMULAIC SEQUENCES' FREQUENCY IN TEXTBOOKS

\begin{tabular}{|ll|l|l|l|l|}
\hline \multicolumn{2}{|c|}{ group } & Number & Means & St. Dev. & SE Mean \\
\hline x1 & Reading-writing & 100 & 8.6700 & 3.54211 & .35421 \\
\cline { 2 - 6 } & Listening-speaking & 100 & 35.5000 & 25.13981 & 2.51398 \\
\hline
\end{tabular}

TABLE 4.

INDEPENDENT T TEST OF FoRMULAIC SEQUENCES' FREQUENCY IN TEXTBOOKS

\begin{tabular}{|c|c|c|c|c|c|c|c|c|}
\hline & \multirow{2}{*}{\multicolumn{2}{|c|}{$\begin{array}{l}\text { Levene's test for } \\
\text { Equality of variance }\end{array}$}} & \multicolumn{6}{|c|}{ T test of mean equation } \\
\hline & & & \multirow[b]{2}{*}{$\mathrm{t}$} & \multirow[b]{2}{*}{ df } & \multirow[b]{2}{*}{ Sig.(2-tailed) } & \multirow[b]{2}{*}{ Mean difference } & \multicolumn{2}{|c|}{$95 \%$ Confidence Interval } \\
\hline & $\mathrm{F}$ & Sig. & & & & & Lower Bound & Upper Bound \\
\hline $\begin{array}{l}\text { Equal variances } \\
\text { assumed }\end{array}$ & 35.114 & .000 & -10.568 & 198 & .000 & -26.83000 & -31.83658 & -21.82342 \\
\hline $\begin{array}{l}\text { Equal variances not } \\
\text { assumed }\end{array}$ & & & -10.568 & 102.929 & .000 & -26.83000 & -31.86518 & -21.79482 \\
\hline
\end{tabular}

\section{B. Functions of Formulaic Sequences}

It is also necessary to study the functions of formulaic sequences, because different modalities may indicate various registers and functional categorizations. According to Hyland (2008), formulaic sequences fall into three brackets: ideational, textual and interpersonal. Ideational formulaic sequences are research-oriented, helping to structure experience and activity of the real world. Textual formulaic sequences deal more with the meaning of text and its organization. Interpersonal formulaic sequences are participant-oriented, focusing on the writer or the reader. Following in this vein, Fig. 1 outlines the percentages of formulaic sequences in integrated and listening-speaking textbooks. From Fig. 1, two features of the functions of formulaic sequences in the two textbooks can be captured. First, the distribution over different types of functional formulaic sequences tends to converge. In both the integrated and the listening-speaking textbooks, interpersonal formulaic sequences occur the most $(62 \%$ for the integrated textbook, and $69 \%$ for the listening-speaking textbook). What follows is ideational formulaic sequences (33\% for the integrated textbook and $31 \%$ for the listening-speaking textbook). However, differences exist in the number of formulaic sequences between the integrated and the listening-speaking textbooks. As can be seen from Fig. 1, ideational and textual formulaic sequences occur slightly more in the integrated textbook than in the listening-speaking textbook, while interpersonal formulaic sequences in the listening-speaking textbook outnumber those in the integrated textbook. 


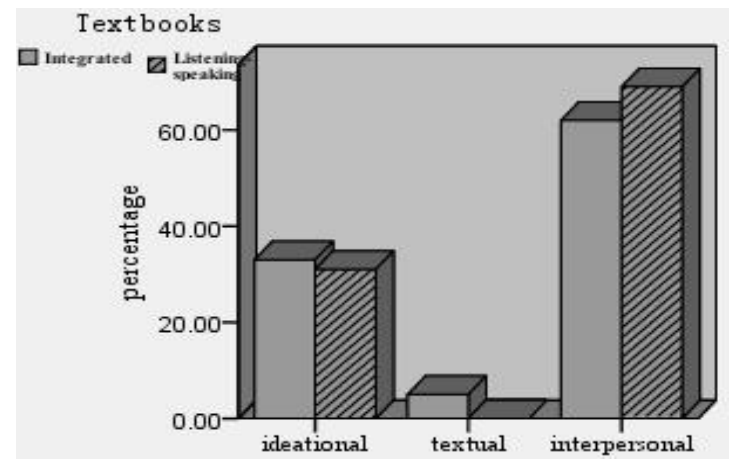

Fig 1. Percentages of Formulaic Sequences Types in Integrated and Listening-speaking Textbooks

According to Hyland (2008), the above ideational, textual and interpersonal formulaic sequences can all be further categorized, as is shown in Table 5. Based on this sub-categorization, the meta-functional formulaic sequences are explored in detail, the results of which are listed in Table 6. For ideational formulaic sequences, more location, quantification and description formulaic sequences occur in the integrated textbook, for instance, out of the, in the world. Procedure and topic formulaic sequences are more likely to be found in the listening-speaking textbook, for example, is going to, the story summary, in the city. There are also a few textual formulaic sequences in the integrated textbook, but none in the listening-speaking textbook. Examples of textual formulaic sequences are as well as, as a result in the integrated textbook. It is worth pointing out that the two textbooks have almost the same amount of interpersonal formulaic sequences. Formulaic sequences like there is no, it was time come from the integrated textbook, while do you think, how would you from the listening-speaking textbook.

TABLE 5.

META-FUNCTIONAL CATEGORIZATION OF FORMULAIC SEQUENCES

\begin{tabular}{|l|l|l|}
\hline Functions & Sub-categorization & Examples \\
\hline \multirow{4}{*}{ Ideational } & Location & at the same time, at the beginning of \\
\cline { 2 - 3 } & Procedure & the use of the, the purpose of the \\
\cline { 2 - 3 } & Quantification & a wide range of, one of the most \\
\cline { 2 - 3 } & Description & the structure of the, the size of the \\
\cline { 2 - 3 } & Topic & in the United States, the currency board system \\
\hline \multirow{4}{*}{ Textual } & Transition signals & on the other hand, in addition to the \\
\cline { 2 - 3 } & Resultative signals & as a result of, it was found that \\
\cline { 2 - 3 } & Structuring signals & in the present study, in the next section \\
\cline { 2 - 3 } & Framing signals & in the case of, on the basis of \\
\hline \multirow{2}{*}{ Interpersonal } & Stance feature & may be due to, it is possible \\
\cline { 2 - 3 } & Engagement features & as can be seen \\
\hline
\end{tabular}

TABLE 6.

META-FUNCTIONAL FORMULAIC SEQUENCES IN INTEGR ATED AND LISTENING-SPEAKING TEXTBOOKS

\begin{tabular}{|l|l|l|l|}
\hline \multirow{3}{*}{ Functions } & Textbooks & Integrated Reading-writing Textbook & Listening-speaking Textbook \\
\hline \multirow{4}{*}{ Ideational } & Location & 10 & 2 \\
\cline { 2 - 4 } & Procedure & 4 & 15 \\
\cline { 2 - 4 } & Quantification & 6 & 3 \\
\cline { 2 - 4 } & Description & 10 & 1 \\
\cline { 2 - 4 } & Topic & 3 & 10 \\
\hline \multirow{5}{*}{ Textual } & Transition Signals & 2 & 0 \\
\cline { 2 - 4 } & Resultative signals & 2 & 0 \\
\cline { 2 - 4 } & Structuring signals & 0 & 0 \\
\cline { 2 - 4 } & Framing signals & 1 & 54 \\
\hline \multirow{3}{*}{ Interpersonal } & Stance feature & 56 & 15 \\
\cline { 2 - 4 } & Engagement features & 13 & 0 \\
\hline
\end{tabular}

\section{Chinese EFL Learners Acquisition of Multi-modal Formulaic Sequences}

In the above sections, attempts have been made to explore the distribution features and functions of formulaic sequences in different modal English textbooks. Differences, sometimes significant differences are found to exist in distribution and function of formulaic sequences between the two textbooks. Then are these input differences in register effective for EFL learners, making them more aware of the differences and choosing appropriate formulaic sequences in different registers. Table 7 lists means of formulaic sequences by Chinese EFL learners at different proficiency levels indicated by the College English Test (the lowerCET4 and the higher CET6) in their composition output. The formulaic sequences compared are the top 10 formulaic sequences presented in Table 1 and Table 2. 
TABLE 7.

LEARNERS' ACQUISITION OF FORMULAIC SEQUENCES IN TEXTBOOKS

\begin{tabular}{lllll}
\hline \multirow{2}{*}{ Formulaic Sequences in Textbooks } & Group & Number & Means & St. D \\
& Listening-speaking & 20 & 78.0000 & 117.69139 \\
\cline { 2 - 5 } & Integrated & 20 & 138.3500 & 230.21644 \\
\hline \multirow{2}{*}{$\begin{array}{l}\text { Formulaic Sequences in Integrated } \\
\text { Textbook }\end{array}$} & CET4-passers & 10 & 152.4000 & 306.36949 \\
\cline { 2 - 5 } & CET6-passers & 10 & 124.3000 & 132.61645 \\
\hline \multirow{2}{*}{$\begin{array}{l}\text { Formulaic Sequences in } \\
\text { Listening-Speaking Textbook }\end{array}$} & CET4-passers & 10 & 69.5000 & 108.08253 \\
\hline
\end{tabular}

The purpose is to see how learners at different proficiency levels use the formulaic sequences learned in the integrated and listening-speaking textbooks. Results (Table 7) indicate that the means of formulaic sequences is higher in the integrated textbook than in the listening-speaking textbook. However, the means of CET4 learners is higher than CET6 learners in the integrated textbook, while the means of CET6 learners is higher than CET 4 in the listening-speaking textbook. In order to test whether there are significant differences between these means, independent $\mathrm{T}$ tests are conducted. Results show that at the level of $\mathrm{P}<0.05$, there is no significant difference in the usage of formulaic sequences between the integrated and the listening-speaking textbooks ( $\mathrm{F}=1.565$, Sig. $=0.219)$, between CET4 learners and CET6 learners in their usage of formulaic sequences both in the integrated textbook $(\mathrm{F}=0.924$, Sig. $=0.349)$ and in the listening-speaking textbook $(\mathrm{F}=0.369, \mathrm{Sig} .=0.551)$. It then suggests that Chinese EFL learners are not sensitive to the register differences despite the input emphasis in multi-modal textbooks in their process of EFL learning.

\section{Pedagogical Implications}

Based on the comparisons of distributional features and functions of formulaic sequences in multi-modal EFL textbooks, the present study finds that the listening-speaking textbook has a much higher frequency than the integrated textbook and these two textbooks highlight different sets of formulaic sequences with distinct meta-language functions. In spite of the prominence in EFL textbooks, Chinese EFL learners seem not to have acquired the register differences, subtle or obvious, in their language output. These research findings have great implications for Chinese college learners' EFL. By drawing on our research findings and the usage-based language theory (Tomasello, 2008), we proposed a model for the acquisition of formulaic sequences (Fig. 2), with the hope of reveal implications for college EFL in the Chinese setting.

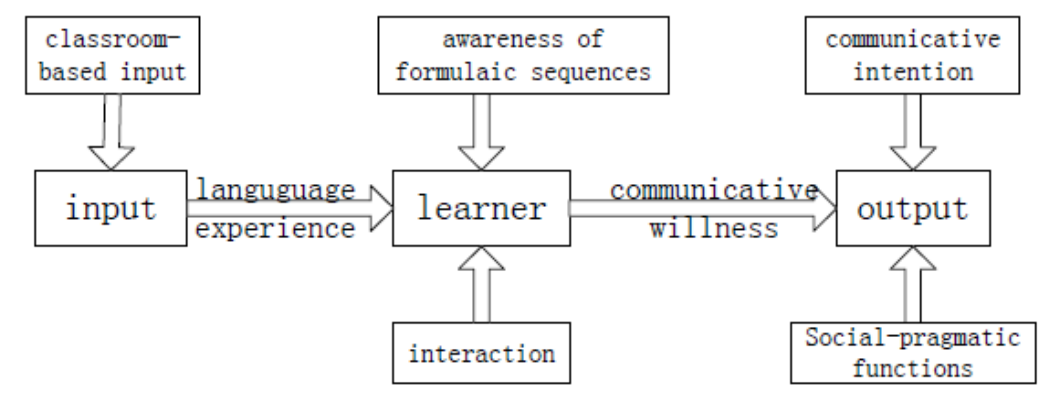

Fig. 2. Model for the Acquisition of Formulaic Sequences

First, great importance should be attached to the high-frequent input of formulaic sequences, which should be classroom-based and of maximum quantity in order to ensure enough language experience. Frequency is a critical factor in deciding whether language input can become intake. It is estimated that a frequency of 8 to 12 per hundred words is needed of a novel word in text before its meaning can be comprehended from inference and its form and meaning retained (c.f. Ellis, 2009). Additionally, high-frequency formulaic sequences are not only more productive but also processed more quickly than low-frequency ones (Ellis, 2009). Reading and writing is different from listening and speaking, because they require very different language skills. Generally, listening and speaking demands a smaller vocabulary which tends to re-occur very often (Saville-Troike, 2006). It is no doubt then that formulaic sequences enjoy a much higher frequency in the listening-speaking textbook than in the integrated reading-writing textbook. In this way, differences in registers are well delineated in textbooks. However, this does not mean that formulaic sequences are less important in reading and writing. On the contrary, learners have to get information and communicate through the means of reading and writing. Therefore, it is of importance to well consider the input frequency of formulaic sequences in multi-modal textbooks, in order to enhance language input and intake. For college learners in China, language input both in and outside the classroom is one of the most efficient and important sources that provide learners with input. Thus, teachers and textbook compilers have to have in mind the way and the order formulaic sequences are presented, and the percentage of formulaic sequences in textbooks.

Reading and writing, and listening and speaking fall into different motor skills with distinct register characteristics. 
As the main language input sources, the respective textbooks include formulaic sequences of varying functions, which is aimed at fostering EFL learners' awareness of register and pragmatics. However, input alone cannot guarantee acquisition. Many Chinese college learners have passed popular authorized English tests like CET4, CET6, but it does not necessarily mean that their language proficiency has been increased. Miao \& Sun (2006) find a plateau effect in beginning and intermediate Chinese learners' acquisition of formulaic sequences. It follows that more attention is paid to the awareness-raising of formulaic sequences in daily EFL learning and teaching process, so that learners can understand the importance of formulaic sequences in their language learning and consciously notice, learn and use them It should be noted that acquisition of formulaic sequences should be driven by interaction, because any language learning needs concrete language experience and usage (Tomasello, 2008). One or two experiences cannot lead to acquisition, for language experience needs repetition, which suggests that interaction might provide learners with the most effective language experience with formulaic sequences. A series of activities and tasks can be designed and carried out in the process of EFL learning and teaching to promote interaction that may lead to the acquisition of formulaic sequences. It is well-worth mentioning that these activities as well as tasks should be well designed in structure and encourage meaning-negotiated interactions.

With high-frequent and register-oriented language input, opportunities to practice language output are also essential. Wen (2006) points out that Chinese EFL learners are not sensitive to oral and written differences in their output, which usually takes the form of mixed styles with no clear-cut register differences. This is the reason why learners cannot always distinguish the functions and pragmatic usages of formulaic sequences despite the register-oriented language input in EFL textbooks. Under this circumstance, language output many come into play, because it helps develop automaticity through practice and because it helps learners notice gaps in their own knowledge (c.f. Saville-Troike, 2006). Language output may serve four functions in EFL learning and teaching (Gass \& Selinker, 2008): receiving crucial feedback for the verification of hypotheses; testing hypotheses about the structures and meanings of the target language; developing automaticity in interlanguage production; and forcing a shift from more meaning-based processing to a more syntactic mode. Formulaic sequences are pre-fabricated language that can be stored, retrieved and used as a whole without the need to compose them on-line through much consideration of word choice and grammar. The ability to use formulaic sequences can not only enhance language fluency, but also contribute to the appropriateness and idiomaticity of language use as well. Therefore, the output of formulaic sequence is crucial to EFL learners. Driven by the learners' intention to communicate, the output can be either student-student or student-teacher interactions. In this process, appropriate feedback should be provided to make it possible for learners to modify and reconstruct their input-based hypotheses about formulaic sequences, and thus thoroughly understand the social-pragmatic functions of formulaic sequences.

\section{CONCLUSION}

Since Lewis' lexical approach in the 1990s, research on the teaching and learning of formulaic sequences has been under way. Yet with different working theories, scholars have adopted a variety of research methods. As a tentative study, we have explored the popular EFL textbooks in China by comparing the distributions, functions and learners' acquisition of formulaic sequences. It is found that multi-modal textbooks differ in the frequency distribution, categories and functions of formulaic sequences. Relevant suggestions have been made for the language input and output in EFL. Future research may focus on the interaction between frequency and saliency of formulaic sequences in EFL and textbook compilations, and the comparison of register differences in the usage or output of oral and written formulaic sequences.

\section{ACKNOWLEDGEMENT}

The research was supported by a grant from Jiangxi Province's Educational Science Program "Chunk Acquisition in Foreign Language Classrooms" (12YB091).

\section{REFERENCES}

[1] Biber, D. (2006). University Language: A Corpus-based Study of Spoken and Written Registers. Amsterdam/Philadelphia: John Benjamins Publishing Company.

[2] Chen, H. Y. \& X. L. Chen. (2012). A corpus-based study of formulaic sequences in a computer English textbook and a general college English textbook. Foreign Language World, (1): 68-72.

[3] Ding, Y. R. \& Y. Qi. (2005). Use of formulaic language as a predictor of L2 oral and written performance. Journal of PLA University of Foreign Languages, 28 (3): 49-53.

[4] Erman, B. \& B. (2000). Warren. The idiom principle and the open-choice principle. Text, 20 (1): $29-62$.

[5] Ellis, N. C. (2009). Optimizing the input: frequency and sampling in usage-based and form-focussed learning. In Michael Long \& Cathy Doughty (eds.) The Handbook of Second and Foreign Language Teaching. Blackwell Handbooks in Linguistics: $139-158$

[6] Gray, B. \& D. (2013). Biber. Lexical frames in academic prose and conversation. International Journal of Corpus Linguistics, 18 (1): 109-136.

[7] Gass, S. \& L. Selinker. (2008). Second Language Acquisition: An Introductory Course. New York: Routledge. 
[8] Hyland, K. (2008). As can be seen: lexical bundles and disciplinary variation. English for Specific Purposes, 27 (1): 4-21.

[9] Huang, Y. \& H. X. Wang. (2011). A survey of researches on L2 chunks in China. Foreign Language World, (1): 74-81.

[10] Koprowski, M. (2005). Investigating the usefulness of lexical phrases in contemporary coursebooks. ELT Journal, 59 (4): 322-332.

[11] Martinez, R. \& N. Schmitt. (2012). A phrasal expressions list. Applied Linguistics, 33 (3): 299-320.

[12] Ma, G. H. (2011). Lexical chunks: definition, categorization and identification. Journal of PLA University of Foreign Languages, (1): 1-4.

[13] Ma, G. H. (2009). Lexical bundles in L2 timed writing of English majors. Foreign Language Teaching and Research, (1): 54-59.

[14] Miao, H. Y. \& L, Sun. (2006). The use of sentence builders and the development of L2 oral fluency. Foreign Language Teaching and Research, 38 (5): 265-271.

[15] Qu, D. D. \& J. Deng. (2010). A corpus-based study of vocabulary learning model. Foreign Language World, (1): 47-53.

[16] Simpson-Vlach, R. and N. C. Ellis. (2010). An academic formulas list: new methods in phraseology research. Applied Linguistics, 31 (4): 487-512.

[17] Saville-Troike, M. (2006). Introducing second language acquisition. Cambridge: CUP.

[18] Tomasello, M. (2008). Origins of Human Communication. Cambridge, Massachusetts: The MIT Press.

[19] Wang, M. \& D. Liu. (2013). A corpus-based study of the use of stance expressions in English research article manuscripts by Chinese EFL learners. Modern Foreign Languages, 36 (2): 190-197.

[20] Wen, Q. F. (2006). A study on vocabulary variation across speech and writing. Foreign Language and Their Teaching, (7): 9-13.

[21] Wray, A. \& M. R. Perkins. (2000). The functions of formulaic language: an integrated model. Language \& Communication 20: 1-28.

[22] Yang, H. Z. (2012). Words to Teachers. In Qin, X. B. (ed), New Century College English Series of Learning to Speak Textbook. Shanghai: Shanghai Foreign Language Education Press: $x-x i$.

Haiyan Miao was born in Wuhu, China in 1979. She received her MA degree in linguistics and applied linguistics in 2005. She is currently a lecturer in the School of Foreign Languages, Jiangxi Normal University. Her research interests include psycholinguistics and second language acquisition. 